\title{
Light Dependant Electronic Controllers for Switching Lamps
}

\author{
K. K. Y. W. Perera and D. A. I. Munindradasa
}

\begin{abstract}
The overall objective of the research is to conserve energy through reducing wastage. This particular work involves innovation and fabrication of devices towards the above objective. The subject presentation of this manuscript is in respect of devices, which will enable domestic, factory as well as street lights to be automatically switched ON at sunset (when darkness arrives) and automatically switched OFF at dawn (when light arrives). Literature survey revealed that several such devices are available but they suffer from many draw-backs such as high energy consumption by the device, flicker (ON \& OFF oscillations) at the critical light level of switching, poor reliability, high space requirements, circuit complications etc. The research has solved these deficiencies and has come up with suitable solid-state devices having no electro-mechanical relays. In particular, the flicker problem needed positive feed-back of some form to give a Schmitt trigger effect. In one case this was solved by an innovative method wherein the very lamp that is turned on (or a pilot lamp) beams a fraction of its light on to an LDR, which in turn strengthens the trigger ON. This innovation allows the Schmitt Trigger effect without a D.C. power supply otherwise required for traditional feed-back. The reduction of energy consumption by the device itself necessitated novel approaches. Suitable prototypes have been designed, fabricated and have been subjected to a limited extent of field testing.
\end{abstract}

Key words: Energy, efficiency, automatic, switching, lights.

\section{Introduction}

In Sri Lanka, the electricity growth rate to GDP growth rate has been keeping to $a$ ratio of approximately $1.5: 1$. In countries where proper attention has been given to Demand Side Management (DSM), such as in Japan where energy consumption is kept low by efficient equipment as well as improved management, the ratio is close to 1:1. Thus, there is much scope in Sri Lanka to influence energy efficiency and cost saving.

Demand Side Management (DSM), is preferable to increasing of generation to meet the unmanaged demand, because of various factors including lower cost and better environment. When the demand rises and such increased demand has to be met by additional generation, in the context of Sri Lanka this impliesincreased thermal generation which is associated with increased emission of Oxides of Carbon, Sulfur and Nitrogen. Therefore, concerted attempts should be made to keep the demand to a minimum, while not compromising with the energy requirements for development and other functional purposes. This can be done through improved efficiency of devices and of energy utilization.
The importance of Energy Efficiency and Demand Side Management are highlighted in a large number of papers which can be cited. It is considered adequate to cite the findings of the study by Japan Bank for International Cooperation (JBIC). In section 2 of the Executive Summary it is stated that Sri Lanka as a whole is estimated to have potential energy savings of Rs.19.5 billion per year [1].

In the above context, a research \& development ( $\mathrm{R} \& \mathrm{D})$ programme was planned to develop several energy saving devices. The subject of this particular research was to design and make prototypes for electronically switching $\mathrm{ON}$ incandescent, fluorescent, sodium vapour and other lamps when darkness arrives (dusk) and switching OFF when light arrives (dawn). Electricity saving through prompt switching of street lamps and other lights can be achieved. The desirable features of such a device were identified as ;
Vidya JyothiEng. (Prof.) K.K. Y.W. Perera, C.Eng, FIE(SL) P. Eng. FIET(Lond.), MIEEE, B.Sc. Eng. (Hons) (Cey), M.Sc.(Birmingham), Ph.D(UBC, Canada), Prof.emeritus, University of'Moratuwa

Dr. D.A.I. Munindradasa, B.Sc. Eng. (hons.) (Moratuwa), Ph.D. (Lond.), Senior Lecturer, University of Moratuwa 
- Completely solid state, without electromechanical relays.

- Freedom from switching oscillations which give rise to lamp flicker, when very gradual sunset or sunrise occurs (light changes). This indicates the need for hystersis backed by snap-on type of latching.

- Low power consumption in the control device itself

- Simplicity and low number of components.

- Low cost.

- Ease of maintenance.

\section{Methodology}

Initially a literature survey was carried out. Because simplicity of the circuit is an important and desirable feature, the initial survey identified the low capital cost device of figure 1 .

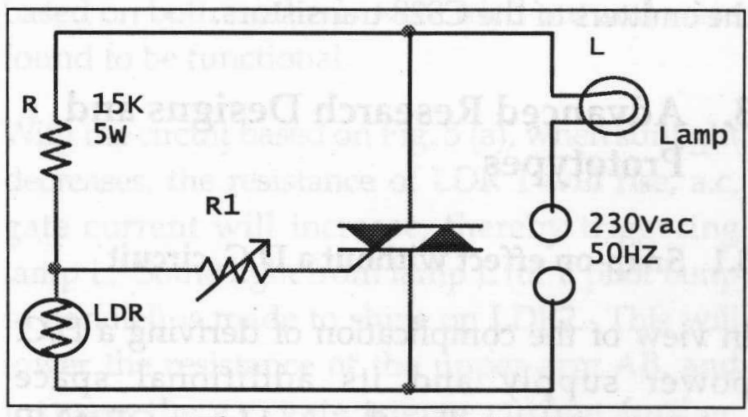

Figure 1: Elementary control circuit for dark activated switch

This elementary circuit is simple and functional but operates with several undesirable effects. The operation itself is very simple. When the light is removed or reduced (night - fall), the resistance of the Light Dependent Resistor (LDR) becomes high. Therefore the current to the gate of the triac increases. The triac will trigger (fire) and lamp will light. Similarly, when the day breaks in the morning, the LDR resistance will become low and a part of the current which comes through $\mathrm{R}$ is diverted away from the gate circuit of the triac, thus switching off the triac and the light.

However the circuit gives rise to several undesirable features including,

1. high power loss in $\mathrm{R}$ (about 5 Watts)

2. the lamp lights with partial brightness at dusk and at dawn.

3. no "Snap-on" effect at switching

4. lamp flickers at boarder line lighting (close to sunset and dawn).

\subsection{Schmitt Trigger Effect}

The simple circuit in Fig. 2, is one of the better circuits derived from literature and modified [3].

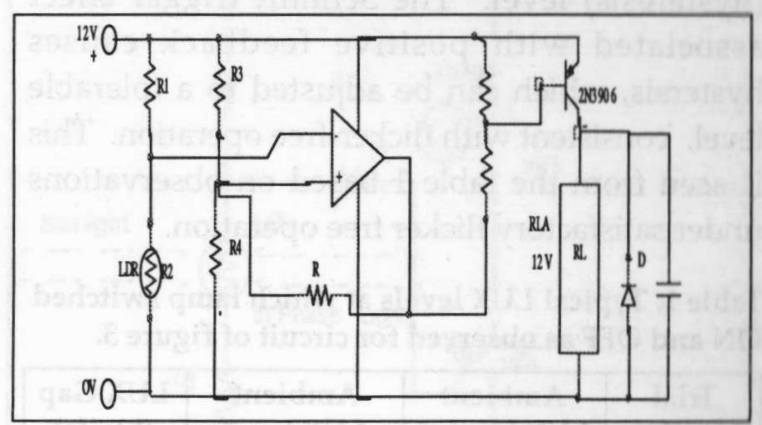

Figure 2: A Switch with Schmitt Trigger Circuit using an OP-AMP and Relay

It will be observed that this is a dark activated switch with hysteresis. When night falls, the relay operates and relay contacts close, causing a $230 \mathrm{~V}$ lamp to light (relay contacts and lamp circuit are not shown in the figure). It will be deenergized at a different light level, due to the Schmitt trigger effect caused by the D.C. positive feed-back from the output of the OP-AMP to the input through the resistor $R$. Thereby the problem of flicker at boarder line lighting is eliminated. Its disadvantages are (a) the electromechanical relay (b) the need for a D.C. power supply to operate the operational amplifier and control circuit, (which adds to the cost and complexity of the device) and (c) high cost.

Because devices with the desired criteria (section 1) could not be found in the literature or the market, this particular R \& D was undertaken.

\subsection{Initial Researched Designs and Prototypes}

A simple circuit which has eliminated the transistor, replaced the electro-mechanical relay with a triac and eliminated the associated diode was designed and fabricated during the research. The circuit is given at figure 3 .

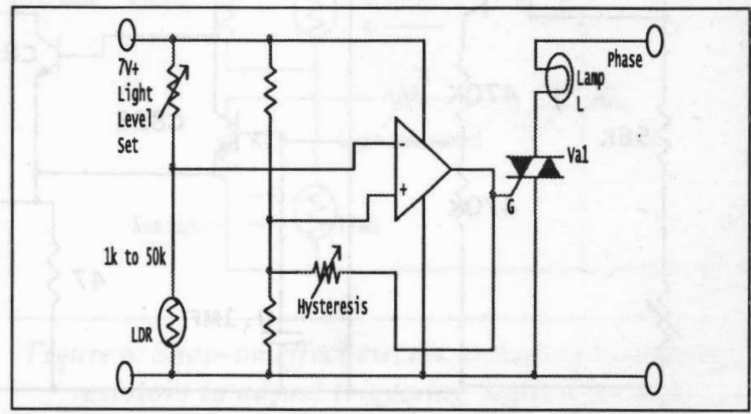

Figure 3: A Fully solid state Switch with Schmitt Trigger action using an op-amp and a triac. 
This circuit was tried out and operated satisfactorily. The circuit incorporates adjustable light triggering level and positive fee-back (hysteresis) level. The Schmitt trigger effect associated with positive feedback causes hystersis, which can be adjusted to a tolerable level, consistent with flicker-free operation. This is seen from the table 1 based on observations under satisfactory flicker free operation.

Table 1. Typical LUX levels at which lamp switched $\mathrm{ON}$ and OFF as observed for circuit of figure 3.

\begin{tabular}{|c|c|c|c|}
\hline $\begin{array}{c}\text { Trial } \\
\text { Number }\end{array}$ & $\begin{array}{c}\text { Ambient } \\
\text { LUX level at } \\
\text { which lamp } \\
\text { switches } \\
\text { ON (a) }\end{array}$ & $\begin{array}{c}\text { Ambient } \\
\text { LUX level } \\
\text { at which } \\
\text { lamp switches } \\
\text { OFF (b) }\end{array}$ & $\begin{array}{c}\text { LUX Gap } \\
\text { (b) - (a) }\end{array}$ \\
\hline 1 & 18 & 22 & 4 \\
2 & 17 & 22 & 5 \\
3 & 15 & 19 & 4 \\
4 & 17 & 21 & 4 \\
\hline
\end{tabular}

The LUX gap observed above is small. It was observed that even with a smaller LUX gap, satisfactory snap-ON effect was possible.

Initially, D.C. power supply was derived from $230 \mathrm{~V} 50 \mathrm{~Hz}$. mains using traditional step-down transformer, rectifier and smoothing methodology. Such a power supply is bulky and expensive. This was improved later by the method described below.

A simpler, light-weight, low-cost power supply required for the OP-AMP circuit was derived from $230 \mathrm{~V}$ a.c. mains using a series capacitor to drop the voltage (without power loss associated with a resistor) and a diode plus a smoothing capacitor. Stabilization using a resistor and Zenner diode was found to be adequate. Selection of a triac which requires low gate triggering current made it possible to keep the power consumption of the power supply and control circuit to below 0.5 Watts.

\subsection{An Industrial Version}

A circuit such as above using an OP-AMP was found to be satisfactory for use in homes of Colombo, where lightning originated or other voltage surges are not severe. An industrial version for adverse environments and for localities where lightning surges are severe, the transistorized version at figure 4 was developed and tested. The positive feed-back and hysteresis effect is brought-in by the resistors on the emitters of the C828 transistors.

\section{Advanced Research Designs and Prototypes}

\subsection{Snap-on effect without a D.C. circuit}

In view of the complication of deriving a D.C. power supply and its additional space requirements as well as the need for an OP-AMP or transistor based feed-back to get the desired Schmitt trigger effect as in figures 3 and 4 , a method of a.c. positive feed-back to introduce a snap on effect to the circuit of figure 1 was seen

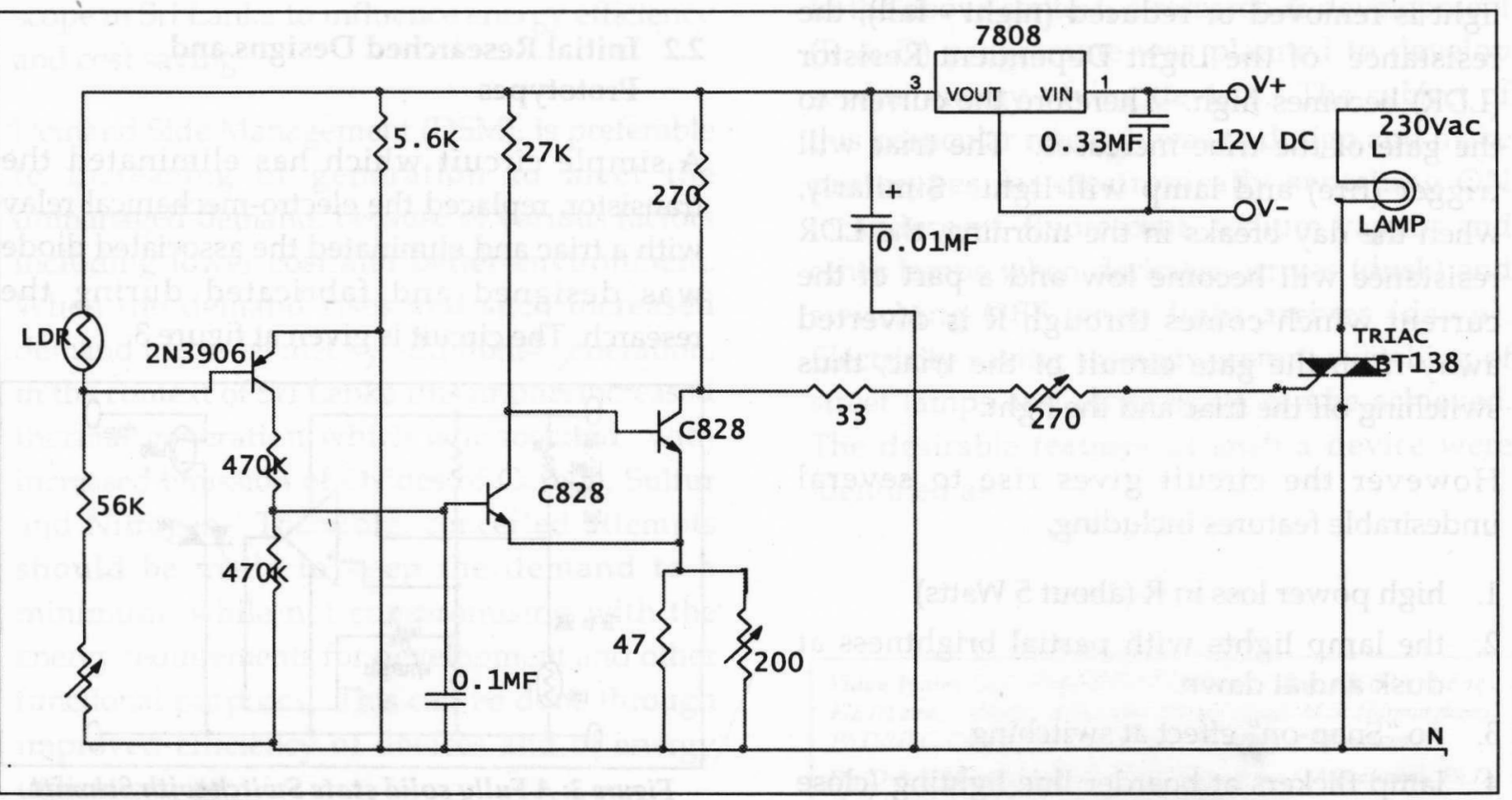

Figure 4: A Switch with Transistorized Version of Schmitt Trigger Circuit for Use in Industrial Environments. 
to be desirable. Because of dealing with an a.c. $50 \mathrm{~Hz}$ triac gate current, it is necessary to add to it a feed-back current in-phase with the $50 \mathrm{~Hz}$ a.c., as soon as darkness switches the lamp ON.

A simple but non-conventional method of devising such a positive feed-back effect was innovated during the research. This is by getting a portion of the light from the actual lamp (which is to be switched ON and OFF) to simulate and strengthen the effect of sunset and day-break. Because the light from the lamp is anti-phase with day light, it can be made to beam on to a second LDR 2 \{figure 5 (a)\}which will enhance and complement the action of LDR 1 to increase gate current. Alternatively light which is in phase with sunlight has to be beamed on the same LDR 1 . The principles of these two novel methods are illustrated in Figures 5(a) and 5 (b) respectively. Circuits based on both methods were tried out and were found to be functional.

With the circuit based on Fig. 5 (a), when sunlight decreases, the resistance of LDR 1 will rise, a.c. gate current will increase, thereby triggering lamp L. Some light from lamp L (or a pilot lamp in parallel) is made to shine on LDR2. This will lower the resistance of the upper arm $\mathrm{AB}$, and increase the a.c. gate trigger current further, exhibiting a positive feed-back effect in phase. Thus, a snap-on effect with hysterisis derived from the light of the lamp itself was achieved. The circuit of Figure 5 (a) is preferred, because it incorporates a degree of compensation on characteristic variations of an LDR which occur due to temperature and other changes. By using two identical LDRs as shown in Figure 5 (a), the effect of such changes can be made to cancel.

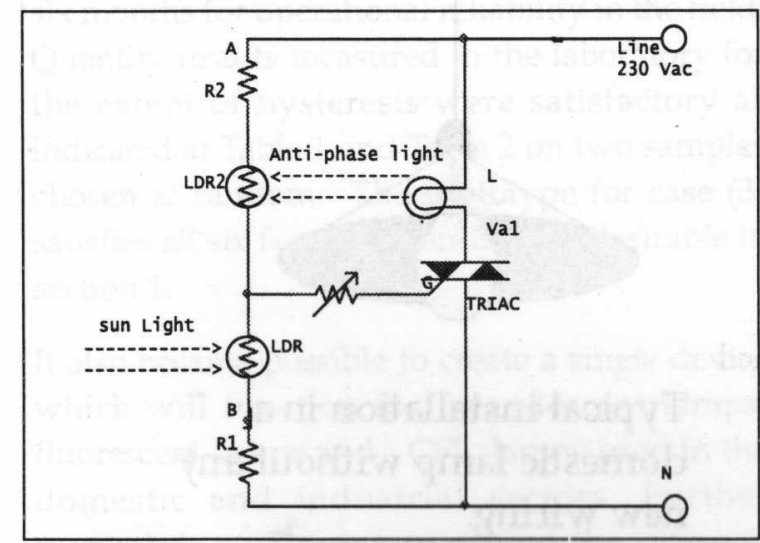

Figure 5 (a) Snap-on effect using lamp light to reinforce sun rise effect

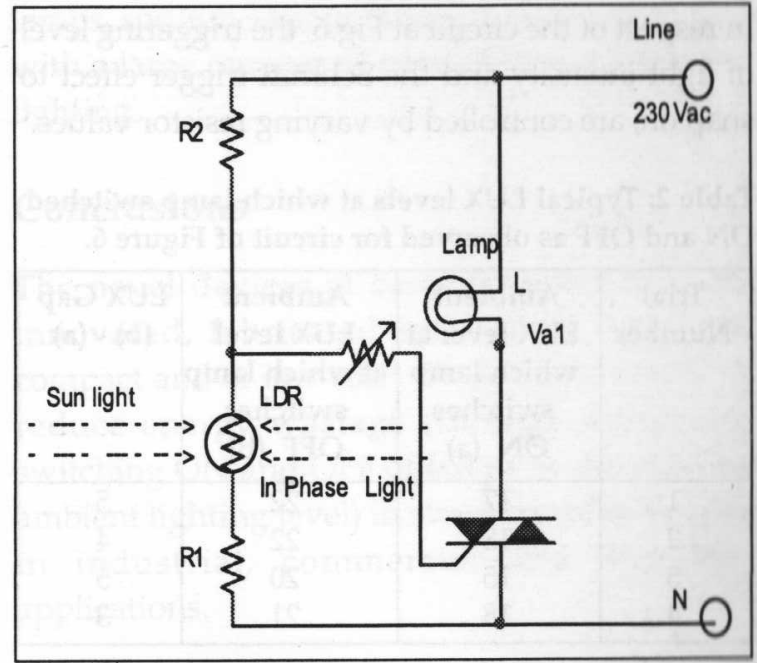

Figure $5(b)$ : Snap-on effect using in-phase light to reinforce sunset effect

In order to vary the extent of feed-back, the proximity of the feed-back (pilot) lamp and the intensity of the pilot lamp were both tried out during different trials. They both gave satisfactory results.

\subsection{Solving the "Half-bright" Problem}

In certain trials it was found that even after full darkness, the lamp lighted at a sub-normal brightness for several minutes and at times even continuously. This was termed "half-bright" problem by the researchers. Analysis and later measurements confirmed that this was due to the triac conducting only during the positive half-cycle of the a.c. voltage, because of reasons given in section 4 under the sub-heading "discussion and conclusions". The half-bright problem was overcome by providing adequate light feed-back and judicious insertion and choice of resistors as indicated at Figure 6.

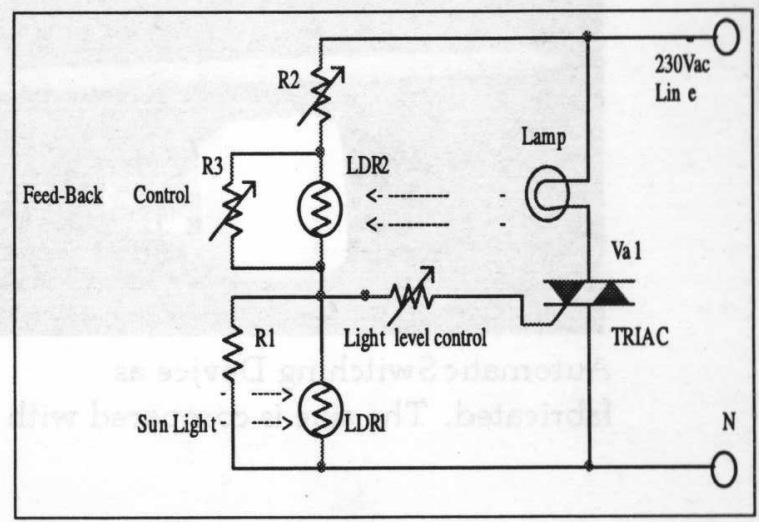

Figure 6: Snap-on effect circuit including balancing resistors to adjust triggering light level and hysteresis effect. No D.C. circuit is used. Hence no D.C. power supply needed. 
In respect of the circuit at Fig.6, the triggering level of light intensity and the Schmitt trigger effect to snap on, are controlled by varying resistor values.

Table 2: Typical LUX levels at which lamp switched $\mathrm{ON}$ and OFF as observed for circuit of Figure 6.

\begin{tabular}{|c|c|c|c|}
\hline $\begin{array}{c}\text { Trial } \\
\text { Number }\end{array}$ & $\begin{array}{c}\text { Ambient } \\
\text { LUX level at } \\
\text { which lamp } \\
\text { switches } \\
\text { ON (a) }\end{array}$ & $\begin{array}{c}\text { Ambient } \\
\text { LUX level } \\
\text { at which lamp } \\
\text { switches } \\
\text { OFF (b) }\end{array}$ & $\begin{array}{c}\text { LUX Gap } \\
\text { (b) - (a) }\end{array}$ \\
\hline 1 & 17 & 22 & 5 \\
2 & 18 & 22 & 4 \\
3 & 15 & 20 & 5 \\
4 & 18 & 21 & 3 \\
\hline
\end{tabular}

3.3 Time at which Switching $\mathrm{ON}$ and Switching OFF Takes Place

Five sample prototypes were tested to gauge the approximate switch $\mathrm{ON}$ and switch OFF times on a clear day, 7th July 2006. (Sun rise and sunset times depend on month and day.) The results are as follows:

Table 3 Test results of Five samples tested for time of SWITCH ON and SWITCH OFF

\begin{tabular}{|c|c|c|}
\hline $\begin{array}{c}\text { Sample Proto- } \\
\text { type Number }\end{array}$ & $\begin{array}{c}\text { SWITCH ON } \\
\text { Time }\end{array}$ & $\begin{array}{c}\text { SWITCH OFF } \\
\text { Time }\end{array}$ \\
\hline 1 & 6.15 p.m. & 6.05 a.m. \\
2 & 6.20 p.m. & 6.10 a.m. \\
3 & 6.18 p.m. & 6.12 a.m. \\
4 & 6.20 p.m. & 6.14 a.m. \\
5 & 6.17 p.m. & 6.13 a.m. \\
\hline
\end{tabular}

The five samples were tested for a period of one month to ascertain reliability. They operated close to times given in the above table, except that slightly early switching $\mathrm{ON}$ and later switching OFF occurred on a cloudy day. This is desirable.

\section{Discussion and Conclusions}

In section 3.2, it was observed that at times the lamp was lighting at partial brightness. The reason for this was not initially clear; subsequent analysis and experiments showed that this was because in these instances, the triac was conducting only during a half cycle of the a.c. mains voltage.

This is due to asymmetric trigger current properties of usual triacs; when anode voltage va1 (figure 6) of the triac is negative it requires more gate current (ig) for the triac to trigger, than when va1 is positive. Though special triacs having better symmetrical properties are manufactured [2], they are not readily available and are more expensive. Therefore, the solution arrived at was to increase (ig) after initial firing, through judicious selection of circuit elements and increased feed-back. When one half-cycle fires, the positive feed-back of such partialbright light was strengthened to enhance the ability to trigger during the balance half-cycle.

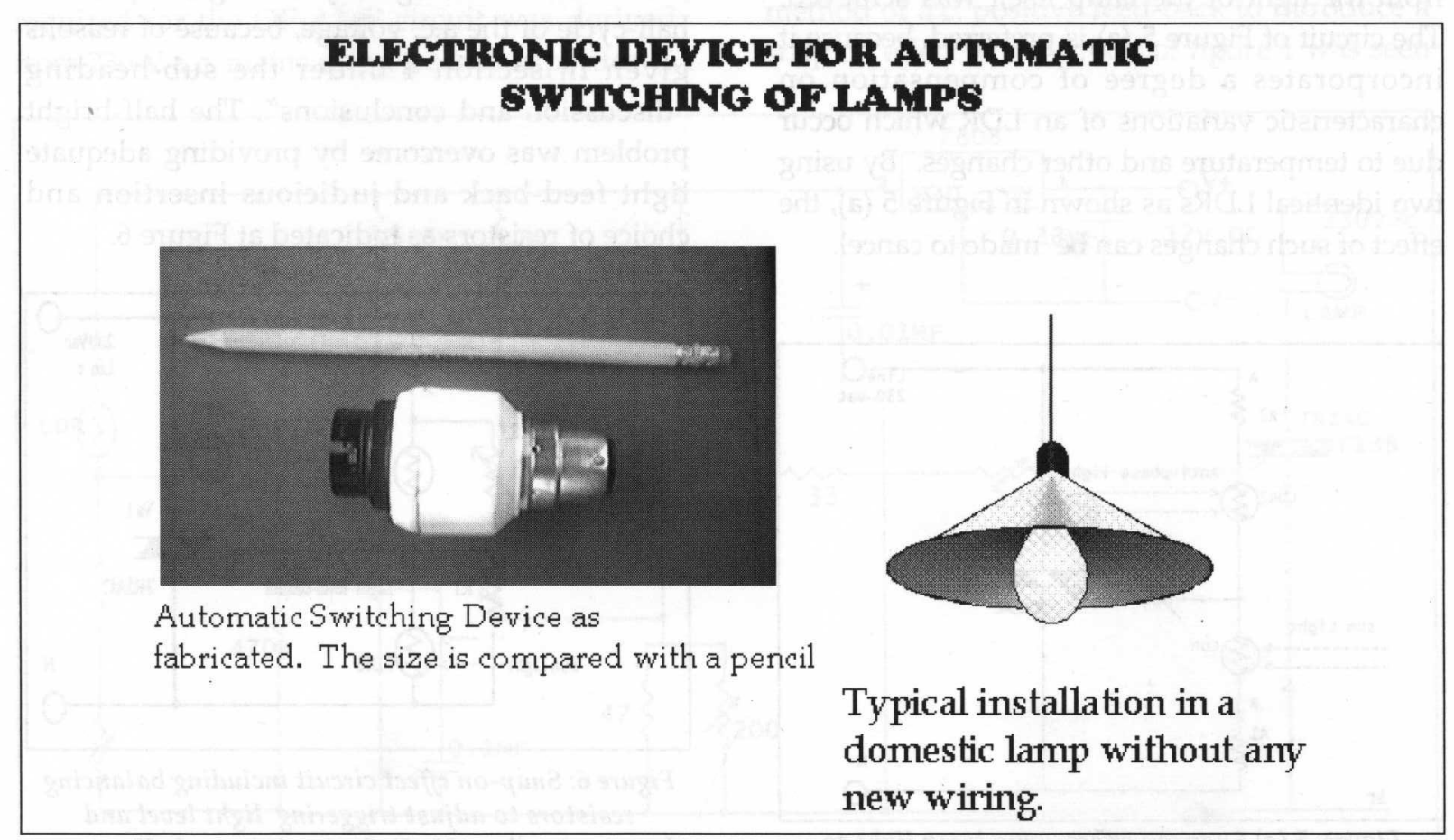

Figure 7: A typical fabricated Proto-type and its application without any new wiring. 


\subsection{Achievements}

The research resulted in the design and fabrication of three types of dark activated solid state switches, suitable for automatically switching ON lamps at night, and switching OFF in the morning. They are:

1. a fully solid state switch using an op-amp and a triac, incorporating a Schmitt trigger circuit to enable latch on effect and elimination of flicker at boarder line sun-set and sun-rise light levels. Five prototypes were tested for over six months and found suitable for homes in Colombo.

2. an industrial version of above using transistors in place of ICs to withstand higher surges.

3. a fully solid state switch using positive feedback from the very lamp that is automatically switched on at sun-set (or using a pilot lamp in parallel with the lamp). Thus, the novel circuit was made to latch with snap-on action using a.c. positive feed-back, to the gate of the triac, this eliminated flicker at boarder-line lighting levels. Adjustable positive feed-back and hysteresis levels are provided. The special feature is that there is no D.C. circuit required normally for positive feed-back and hence this circuit does not need a D.C. power supply, transistors or IC circuits. Hence it has become a very rugged, compact and low cost device suitable for domestic applications as well as for industrial environments with noise.

In cases (1) and (3), a compact version was fabricated successfully as shown at Fig.7 and five numbers of each were tested for more than six months for operational reliability in the field. Quantity results measured in the laboratory for the extent of hysteresis were satisfactory as indicated at Table 1 and Table 2 on two samples chosen at random. The prototype for case (3) satisfies all six features identified as desirable in section 1 .

It also became possible to create a single device which will function for incandescent lamps, fluorescent lamps and CFL lamps used in the domestic and industrial sectors. Further research is continuing to extend the range to encompass high wattage mercury vapour lamps, sodium vapour lamps as well as to a line with a large number of parallel lamps for street lighting.

\section{Conclusions}

The novel devices at cases (1) and (3) were innovated, fabricated and tested. They are compact and of low cost. Their use is bound to reduce energy wastage (through automatic switching ON and OFF of lamps at the desired ambient lighting level) in street lamps as well as in industrial, commercial and domestic applications.

\section{Acknowledgement}

The authors wish to acknowledge with thanks the support given by the National Science Foundation (NSF) by funding, and the University of Moratuwa through laboratory and other facilities. Authors also wish to place on record the contribution by Research Student Mr.P.Wijewardena and the Technical Assistant Mr.Rasika Perera.

\section{References}

1. Pilot study on Energy Efficiency Improvement Fund Project in Sri Lanka, Japan Bank for International Cooperation (JBIC), 2004, Executive Summary pp. 1 - 3.

2. General Electric Silicon Controlled Rectifier manual, including the Triac, Semi conductor Products Department, GE, Syrocuse 1, NY., 1968, pp 161 - 166.

3. Marston R.M, Power Control Circuits Manual, 2nd ed,., 1997, Newnes, pp 46-48 